\title{
La salud materno-infantil en los cuadernos médicos-sociales. Análisis histórico de los mandatos familiares durante la dictadura cívico-militar en el sur de Chile, 1973- 1990.
}

\author{
Maternal and child health in medical-social notebooks. Historical analysis of family \\ mandates during the civic-military dictatorship in southern Chile, 1973-1990.
}

\author{
Marcela Vargas Cárdenas* \\ María José Leiva Vargas ${ }^{* *}$
}

\section{RESUMEN}

Las políticas públicas dirigidas a las familias más pobres, en el marco de la dictadura de Pinochet, provinieron del área de la salud y el desarrollo social, por lo que analizamos los discursos presentes en los Cuadernos médico-sociales considerando la maternidad y la ruralidad en el sur de Chile, con énfasis en la historia social con perspectiva de género. Nuestra hipótesis es que se modernizó el sector salud para dar mayor énfasis a la medicina preventiva, dirigida a los grupos más vulnerables y desprotegidos, como las madres embarazadas y la infancia, desde un enfoque geopolítico; sin embargo, el Colegio Médico, a través de los Cuadernos médico-sociales, representa la heterogeneidad y las tensiones respecto a los discursos y mandatos ligados a la maternidad y las relaciones infanto-maternas, sobre todo en algunas críticas a la cartera ministerial y la falta de recursos.

Palabras clave: maternidad, ruralidad, mandatos familiares, discursos biomédicos, dictadura.

\section{ABSTRACT}

Public policies addressed to the poorest families during the Pinochetist Dictatorship came from the area of health and social development, therefore, we analyzed the discourses in the Cuadernos médicosociales considering motherhood and rurality in southern Chile, with an emphasis on social history with a gender perspective. Our hypothesis is that the health area was modernized to give greater emphasis to preventive medicine aimed at the most vulnerable and unprotected groups of people, such as

\footnotetext{
* Profesora de Historia y Ciencias Sociales, Licenciada en Historia y Magíster en Historia del Tiempo Presente por la Universidad Austral de Chile. Actualmente, es profesora auxiliar adjunta del Instituto de Historia y Ciencias Socia les de la Universidad Austral de Chile, Chile. ORCID: https://orcid.org/0000-0002-3484-7029. Correo electrónico: marcela.vargas@uach.cl.

** Profesora de Historia y Ciencias Sociales, Licenciada en Historia por la Universidad Austral de Chile y Máster en Estudios de Género y Desarrollo Profesional por la Universidad de Sevilla. Actualmente, se encuentra realizando su doctorado en la línea de Historia Contemporánea del Doctorado en Historia y Arqueología de la Universidad Complutense de Madrid gracias al programa de Becas Chile de la Agencia Nacional de Investigación y Desarrollo (ANID) del Gobierno de Chile. ORCID: https://orcid.org/0000-0003-0921-4876. Correo electrónico: maria.jose_leiva@hotmail.com.
} 
pregnant mothers and children, from a geopolitical perspective. However, the Medical College of Chile, through the Cuadernos médico-sociales, represents the heterogeneity and tensions regarding the discourses and mandates related to motherhood and child-maternal relationships, especially in some criticisms of the Ministry of Health and the lack of resources.

Keywords: motherhood, rurality, family mandates, biomedical discourses, dictatorship.

Recibido: marzo 2020

Aceptado: marzo 2021

\section{Introducción}

Estudiar la ruralidad en dictadura nos evoca a los procesos ligados a la Reforma Agraria y estructura patronal, que ha sido motivo de análisis historiográfico, sobre todo en la zona centrosur del país. Si pensamos en estudios de género y ruralidad, historiadoras como Heidi Tinsman y Ximena Valdés han trabajado el impacto de estos procesos en las mujeres campesinas del valle central. Sin embargo, hay aspectos vinculados al sur austral de Chile que no se han historiado. Uno de estos es el impacto del Servicio Nacional de Salud (SNS) en la ruralidad del sur de Chile, en donde mujeres y niños son parte del relato omitido o relativizado. Para estos efectos, buscamos contribuir no solo a la historia social de la salud, sino también a los estudios de género y ruralidad desde la historiografía, y en donde la maternidad emerge como anexo a los estudios de la vida privada, la familia o la infancia.

La revista Cuadernos médico-sociales, fundada en 1959, permite adentrarnos en el discurso experto y experiencial de profesionales del área de la salud (principalmente médicos, ya que la revista pertenece a ese Colegio), que vivieron las transformaciones de las políticas de salud al mismo tiempo que los avances de la medicina a nivel nacional e internacional. Sin embargo, la orientación iba más allá de la formación profesional de trabajadoras y trabajadores de la salud, sino preguntarse por los contextos y realidades de Chile durante las décadas escogidas para el análisis.

A partir de lo anterior, nos surgen las siguientes preguntas ¿qué discursos biomédicos específicos se elaboraron en los Cuadernos médico-sociales y se dirigieron a las madres rurales del sur de Chile durante la dictadura cívico militar (1973-1990)? ¿Qué relación tienen estos discursos con los mandatos familiares de la dictadura cívico militar? ¿Existen diferencias discursivas en las distintas publicaciones, a propósito del rol del Colegio Médico?

Planteamos como hipótesis que los Cuadernos médico-sociales encarnan una tensión discursiva entre el control y el descontrol de los cuerpos de las madres campesinas del sur de Chile, debido a los diversos posicionamientos de médicos no solo respecto a la dictadura, sino también en relación con la realidad campesina y alejada del centro político administrativo. Esto 
último se expresa a través de las reflexiones presentes en los artículos de los Cuadernos médicosociales, con defensas de la medicina social y críticas implícitas a la administración dictatorial, que conviven con el rol del Colegio Médico fuera de la revista, donde incluso algunos abogaron por la necesidad de un Estado separado de la gestión en salud. Esto se evidenciaría en las propias transformaciones que impactan en la salud pública, sobre todo con la desaparición del Servicio Nacional de Salud a fines de la década de los setenta, y la paulatina privatización del sector. Vemos que dependiendo de la formación profesional y el trabajo en espacios periféricos o con dificultades de acceso, se desplegaron aseveraciones críticas respecto al manejo administrativo de la cartera ministerial de salud, al mismo tiempo que respaldos a algunos mandatos referidos sobre todo a la relación infanto-materna.

Nuestro método se basó en la revisión y análisis de diecisiete artículos presentes en los ejemplares de Cuadernos médico-sociales entre 1959 y 1983. Se precisaron aquellos que tuvieran relación con mujeres rurales, siendo recurrentes las referencias a su rol como madres en período de lactancia o en edad reproductiva. Además de estos artículos, trabajamos con anuarios de atención y recursos del Ministerio de Salud entre 1973 y 1990, en el marco de las categorías teóricas planteadas: género, maternidad y ruralidad, para establecer una relación entre la aparición de mujeres rurales en los estudios de Cuadernos médico-sociales, y la atención que recibieron éstas, considerando que principalmente lo hacían a través de las visitas domiciliarias. Establecemos que tanto las reflexiones profesionales como las estadísticas presentes en los respectivos documentos nos permitirán responder a las preguntas de investigación planteadas, en correlato con las presencias y ausencias teóricas que sustentan la problemática.

\section{Sobre la categoría de género y la maternidad para el análisis histórico}

Desde estos lineamientos, con la categoría de género estamos contribuyendo a mirar la diferenciación de roles existentes en los espacios donde se desenvuelve la madre. Debemos pensar a la mujer como sujeto histórico, como mujer-en-el-mundo, situada en un espaciotiempo, y que dialoga con el capitalismo en su fase neoliberal.

Carole Pateman define al género como concepto de contraposición al patriarcado, donde se naturaliza una sujeción de la mujer respecto al hombre producto de la biología como promotora de la diferencia sexual: "Referirse al género y no al sexo indica que la posición de la mujer no está dictada por la naturaleza, por la biología o por el sexo, sino que es una cuestión que depende de un artificio político y social”"

Siguiendo con este planteamiento, Joan Scott presenta al género como categoría útil y relevante para la historiografía al explicar que es un elemento central en las relaciones sociales

\footnotetext{
1 Pateman, Carole; Agra Romero, María José. 1995. El contrato sexual. Vol. 87. Iztapala, Anthropos Editorial, 1995, p. 308.
} 
basadas en la diferencia sexual ${ }^{2}$. Para ella, existen cuatro elementos que se relacionan entre sí y que constituyen lo que entendemos por "género": los símbolos culturales; las normas que definen el comportamiento sexual; las instituciones y organizaciones sociales que construyen también el género, como la familia; $y$, por último, la identidad subjetiva ${ }^{3}$.

Además, el género constituye una primera relación de poder porque la carga simbólica atribuida a la diferencia sexual es la base sobre la que se estructura y organiza toda la vida social. Así, el género legitima y construye las relaciones sociales, creando dinámicas particulares y contextualmente específicas en diferentes momentos históricos y lugares ${ }^{4}$, lo que "obliga a historizar las formas en las cuales el sexo y la diferencia sexual han sido concebidos" ${ }^{5}$, considerando que esas experiencias varían según variables como la clase, la etnicidad, la cultura, la religión y la geografía ${ }^{6}$. O como plantea Nerea Aresti, la tarea desde la historia está en "analizar cómo el género construye la política y cómo la política construye el género"7.

En este sentido, Scott expone que los cambios que modifican las relaciones sociales de género pueden ser promovidos por parte de los Estados y sus necesidades ${ }^{8}$. Como es sabido, la ciudadanía moderna excluyó a las mujeres delimitando así una esfera pública y masculina por excelencia, mientras que las mujeres y la familia pertenecerían a la esfera privada/doméstica. Nira Yuval-Davis afirma que esta supuesta independencia entre ambas esferas es ilusoria, ya que es el Estado quien construye y vigila las relaciones sociales en el ámbito doméstico ${ }^{9}$. Así, puede interferir en el espacio privado estableciendo diferentes derechos o deberes para las mujeres, dependiendo de su clase o etnicidad, por lo que las mujeres estarían siempre incluidas en el Estado y sus proyectos sociales, políticos y económicos ${ }^{10}$.

Por otro lado, Yuval-Davis aclara que el género es funcional a la construcción cultural de las colectividades, simbolizando las mujeres muchas veces el "honor patrio", las raíces y el proyecto de la nación, cumpliendo el papel de reproductoras biológicas, culturales y políticas de la misma ${ }^{11}$. De este modo, es fundamental el control del cuerpo de las mujeres, ya que la manera preferente de pertenecer a la nación es haber nacido en ella, teniendo las mujeres la

\footnotetext{
2 Scott, Joan. 1996. El género: Una categoría útil para el análisis histórico, Lamas, Marta (comp.), El género: la construcción cultural de la diferencia sexual, México, PUEG, 1996, p. 297.

${ }^{3}$ Scott, Joan, El género..., pp. 297-299.

${ }^{4}$ Ibídem, p. 290.

${ }^{5}$ Scott, Joan. 2011. Género: ¿todavía una categoría útil para el análisis?, La manzana de la discordia, Enero - Junio, Año 2011, Vol. 6, N¹, p. 100.

${ }^{6}$ Scott, Joan, Género: ¿todavía..., p. 98.

${ }^{7}$ Aresti, Nerea. 2006. La categoría de género en la obra de Joan Scott en Borderías, Cristina (Ed.), Joan Scott y las políticas de la historia, Barcelona, Icaria Editorial, 2006, p. 226.

${ }^{8}$ Scott, Joan, El género..., p. 234.

9 Yuval-Davis, Nira. 1996. Género y nación: articulaciones del origen, la cultura y la ciudadanía, Arenal: Revista de historia de mujeres, ISSN 1134-6396, Vol. 3, N², Granada, 1996, p. 168.

10 Yuval-Davis, Nira, Género y nación..., p. 169.

${ }^{11}$ Ibídem, p. 170.
} 
"función biológica real de parir hijos"12, ajustándose las políticas de natalidad exclusivamente a las necesidades de la nación o el Estado.

Relacionado estrechamente a lo anterior, Carol Arcos Herrera denomina «la biopolítica de lo materno" a la estatización y nacionalización de la maternidad, a través de las cuales se regula y racionaliza la procreación en beneficio de la patria, comprendiendo ya el cuerpo de las mujeres como un cuerpo individual y a la vez político: "las madres del Estado tienen la labor -el trabajo- de parir y cuidar el nacimiento de la nación"13. En otras palabras, el nacimiento ya no es solo su dimensión biológica, sino que también política al estar íntimamente relacionado a la pertenencia a una comunidad de sentido nacional.

Asimismo, explica que para el caso latinoamericano, la medicalización de la maternidad por parte del Estado a través de la institucionalización de la salud materno-infantil desde una mirada eugenésica e higienista ${ }^{14}$ que, en el caso de Chile, se extenderá por casi todo el siglo XX, está intrínsecamente relacionada con la exaltación de la madre por el sufragismo como mecanismo para la consecución del voto femenino al argumentar que su presencia en la dimensión cívica podría transformar las relaciones públicas desde la abnegación y moralización.

No obstante, la maternidad como objeto de estudio histórico se ha estudiado mayoritariamente como un fenómeno social y político en su dimensión nacional y urbana, pero pocas veces relacionada al mundo rural, componente trascendental de la sociedad chilena del siglo XX.

La presencia de la mujer en el campo chileno estaba subordinada a la del hombre como inquilino y también al patrón, reflejo de la posición social del campesinado frente a la oligarquía terrateniente. Por lo tanto, la maternidad garantizaba la seguridad de la mujer, ya que, en caso de fallecimiento del cónyuge, tener hijos varones que reemplazaran la fuerza de trabajo perdida podía evitar que fueran expulsadas de la hacienda, situación que perduró incluso hasta mediados del siglo $\mathrm{XX}^{15}$.

Las transformaciones políticas, económicas y sociales en Chile durante la década de 1960 y 1970, que levantaron el proceso de reforma agraria y la consecuente organización del campesinado, repercutieron directamente en las relaciones de género del mundo rural. Ejemplo de esto son la proliferación de Centros de Madres rurales, programas de educación, alfabetización y salud sexual y reproductiva con la llegada de los métodos de anticoncepción al

\footnotetext{
12 lbíd., p. 171.

13 Arcos, Carol. 2018. Feminismos latinoamericanos: deseo, cuerpo y biopolítica de lo materno, Debate Feminista, Año 28 , Vol. 55, p. 30.

14 Ibídem, pp. 48-49.

15 Oxman, Verónica. 1983. La participación de la mujer campesina en organizaciones: los Centros de Madres rurales, Santiago, Grupo de Investigaciones Agrarias, Academia de Humanismo Cristiano, p. 3.
} 
campo en el gobierno de Frei Montalva ${ }^{16}$. En el caso de los Centros de Madres en la ruralidad del sur de Chile, encontramos un despliegue comunitario de mujeres campesinas que se agruparon en varias sedes y coordinaron apoyo autogestionado hasta el golpe militar. Algo que prevaleció, sin embargo, fue el uso de estas sedes como espacio de atención médica o de apoyo al trabajo del Servicio Nacional de Salud. Muchos de estos espacios dejaron de existir o fueron "refundados", redirigiendo en algunos casos la acción, para fomentar la superación individual de las mujeres rurales. Asimismo, solo aquellas que participaron con el afán de apoyo comunitario y fueron adherentes de la Unidad Popular dejaron de habitar estos espacios, ya que muchas otras mujeres con tradición campesina portaban historicidad asociada a ser "dueñas de casa", madres y esposas que sostuvieran la autosubsistencia minifundiaria ${ }^{17}$.

Por otra parte, el programa de la reforma agraria buscó la modernización del campo más allá de la reorganización de la propiedad y el trabajo de la tierra; además promovió la instauración de la "familia moderna". Sin embargo, este mandato familiar no transformó en profundidad la división sexual del trabajo, puesto que apuntó a que los hombres se convirtieran en reales proveedores para sus familias y productores, mientras que las mujeres perfeccionarían su rol de ama de casa para adaptarlo a su versión moderna: "mucho más educada, capaz de criar niños y administrar los bienes familiares según normas higiénicas y racionales" ${ }^{18}$. Su trabajo para la reproducción de la vida en el campo fue invisibilizado como labor productiva a partir de un sesgo de género, estableciendo que los propietarios de la tierra eran quienes la trabajaban, los campesinos varones. En ese sentido, la Unidad Popular no buscó liberar a las mujeres campesinas como trabajadoras, sino que, en su calidad de madres, estableciendo la complementariedad de los roles de hombres y mujeres en una familia ${ }^{19}$, aunque eso significó distintos tipos de resistencia por parte de los varones al no querer perder privilegios sexuales y sociales.

Desde la historiografía, por lo tanto, la maternidad se muestra bajo un lente que hace medio siglo ha dejado de verla como un hecho biológico y atemporal y ha comenzado a analizarla como un hecho social. Desde entonces, se ha abordado desde diferentes perspectivas, las cuales Mónica Bolufer sintetiza en tres grandes enfoques: primero, los discursos sobre la maternidad, ya sean religiosos, morales o científicos; segundo, la maternidad estudiada como institución social regida por leyes y costumbres que regulan los mandatos familiares y las relaciones sociales con otras mujeres, con la comunidad y las autoridades, evidenciando

\footnotetext{
16 Tinsman, Heidi. 2008. "La tierra para el que la trabaja: política y género en la reforma agraria chilena", en Perspectivas, Revista de Trabajo Social, Universidad Católica Silva Henríquez, Año XIII, N 19, Santiago, p. 56.

17 Vargas, Marcela. 2020. "No queremos ser servidas, queremos servir a Chile. Rol de los Centros de Madres (CEMA) en el sur rural de Chile, 1973-1983", en Revista Austral de Ciencias Sociales, №39, Valdivia, pp. 75-94.

18 Tinsman, Heidi, La tierra para..., p. 57

19 Ibídem, p. 58.
} 
relaciones de poder y de subordinación; y tercero, las experiencias y subjetividades de las mujeres en la vivencia particular de sus maternidades a partir de sus escritos y relatos de vida. ${ }^{20}$

Si bien el primer enfoque es el más trabajado dentro de los estudios históricos de la maternidad y es precisamente en el cual se enmarca este artículo, es necesario señalar que el presente trabajo encuentra su nacimiento en investigaciones desarrolladas recientemente por las autoras de forma individual ${ }^{21}$, en las cuales -aunque involucren de una u otra forma los tres enfoques de Bolufer-se intenta profundizar en las subjetividades de las mujeres-madres como sujetas históricas. Por esto, con el objetivo de dedicar mayor atención y minuciosidad a cierto tipo de fuentes históricas, se han aunado los esfuerzos en profundizar, a continuación, en los discursos expuestos en los Cuadernos médico-sociales.

\section{Políticas públicas dirigidas a las madres: salud y planificación familiar durante la dictadura civil militar chilena}

El camino de la salud pública en Chile lo entendemos atravesado por la caridad y la dominación ${ }^{22}$, considerando los diferentes momentos de sobrevivencia de la población. Desde los problemas de salubridad generados por la migración campo-ciudad y la "cuestión social", la relación madre-niño propuesta los primeros años de 1900 por Luis Calvo Mackenna atraviesa la salud pública y las formas con las que el Estado se dirigió a las clases populares.

Durante la primera mitad del siglo XX, el discurso dirigido a la madre aboga por lo vital de su vínculo con la infancia y la importancia de la salubridad en este proceso (como la distribución de la leche, hacia 1950$)^{23}$, cuestión que presenta una continuidad visible en los diagnósticos de las visitadoras sociales ${ }^{24}$, la intelectualidad médica ${ }^{25}$ y los posteriores relatos de los Cuadernos Médico-Sociales. El Estado, en su afán modernizador, buscó erradicar la caridad para pasar a la protección social: "gran parte de este movimiento se produce a través de las políticas de salud

\footnotetext{
20 Bolufer, Mónica. 2010. "Madres, maternidad: nuevas miradas desde la historiografía” en Franco Rubio, Gloria (Ed.), Debates sobre la maternidad desde una perspectiva histórica (siglos XVI-XX), Barcelona, Icaria Editorial, pp. 5556.

${ }^{21}$ En el caso de Marcela Vargas, en su investigación de tesis de Magíster en Historia del Tiempo Presente, mientras que María José Leiva se encuentra todavía desarrollando su investigación de tesis doctoral en Historia Contemporánea.

22 Illanes, Angélica. 1993. En el nombre del pueblo, el Estado y la ciencia. Historia social de la salud pública, Chile, 1880-1973: hacia una historia social del Siglo XX, Santiago de Chile, Colectivo de Atención Primaria p. 22.

${ }^{23}$ Según las Actas de las Primeras Jornadas Chilenas de Salubridad, la distribución de la leche hacia 1950, el mayor racionamiento de leche era para las mujeres que están amamantando, Ortiz, Yolanda., Fardella Nora, Godoy, María, Actas de las primeras jornadas chilenas de salubridad organizada por la Sociedad Chilena de Salubridad y Medicina Pública. Santiago, Chile, Talleres de la Casa Nacional del Niño, 1952. Disponible en Memoria Chilena, Biblioteca Nacional de Chile http://www.memoriachilena.cl/602/w3-article-65965.html, p. 6.

24 Illanes, Angélica, En el nombre del pueblo, el Estado y la ciencia. Historia social de la salud pública, Chile, 18801973: hacia una historia social del Siglo XX. Santiago de Chile, Colectivo de Atención Primaria, 1993

25 Poblete, Javiera, Ni madres ni padres. Sexualidad popular en Chile, 1927-1937, Santiago, CENALTES Ediciones, 2019.
} 
pública que culminan con el servicio unificado de salud y con la creación del Servicio Nacional de Salud, en 1954 (sic)"26. Desde su creación, el SNS además promovió una serie de medidas infanto-maternas, sobre todo respecto a un problema que persistió en los estudios de los Cuadernos médico-sociales durante las próximas décadas: la desnutrición. ${ }^{27}$

Como lo indican Tetelboin y Salinas, al menos hasta 1973, la salud se concibió como un derecho que debía entregar el Estado y que era "inalienable de la población" ${ }^{28}$. Junto a la fuerte presencia del Estado en materia de planificación familiar, hacia 1972 la Unidad Popular firmó un convenio "con el Fondo de Población de las Naciones Unidas para un programa trienal de Extensión de Servicios de Salud Materna e Infantil y Bienestar Familiar (PESMIB), paralelo al ya existente entre el SNS y APROFA" 29 . Esto reafirma los intentos por fortalecer los programas que se dirigieran a madres y niños, ya que el despliegue del Servicio Nacional de Salud no era suficiente. En relación al PESMIB, el médico Luis Givovich, quien durante los primeros años de dictadura asumió como subsecretario y Ministro de Salud Pública subrogante ${ }^{30}$, desarrolló un diagnóstico de la salud materno-infantil hacia 1973, en donde enumeró las falencias que seguían afectando la atención de mujeres madres en la época, desde la falta de camas y hacinamiento hospitalario, hasta la crítica al Programa de Planificación Familiar, que "solo mantiene preocupación por la regulación de la fertilidad minimizando todas las otras acciones que una concepción adecuada exige ${ }^{\prime 31}$. Considerando la existencia de un sesgo ideológico en las críticas que recibió la Unidad Popular durante su gestión política, creemos relevante visibilizar las lecturas que hicieron personeros políticos de la época a las políticas de salud pública, ya que son antesala para el giro neoliberal que tendrá la salud hacia la década de los ochenta.

En relación con las políticas de planificación familiar dirigidas a las madres durante la Unidad Popular, estas buscaron no solo disminuir la natalidad y hacer crecer la economía, sino llegar a las mujeres de cualquier clase social, para "mejorar la calidad de vida de su familia, disminuir algunos riesgos biológicos del niño menor, de la madre y limitar la práctica del aborto inducido

\footnotetext{
${ }^{26}$ Araujo Kathya y Valdés, Ximena. 1998. Vida privada: modernización agraria y modernidad. Santiago, CEDEM, p. 83.

${ }^{27}$ Mardones, Francisco. 1980. "Una estrategia educativa para el fomento de la lactancia materna" Cuadernos médicosociales, vol. XXI, Santiago, p. 97

${ }^{28}$ Tetelboin Carolina y Salinas, Darío. 1984. "Estado y políticas de salud en Chile: el proceso de conformación de un nuevo proyecto para el sector salud, 1973-1979", Estudios Sociológicos II, № 2-3, Ciudad de México, p. 358.

${ }^{29}$ Asociación Chilena de Protección de la Familia (APROFA), Investigaciones sobre planificación familiar, Santiago, 1976, p. 33. Disponible en línea en http://www.memoriachilena.cl/archivos2/pdfs/MC0056034.pdf

${ }^{30}$ Respecto a Luis Givovich Mercier se pueden encontrar una serie de decretos con fuerza de ley donde él suscribió como subsecretario subrogante de Salud (1975) y Ministro de Salud subrogante (1976). Por ejemplo, en la modificación del Artículo $4^{\circ}$ de la Ley 16.781, sobre medicina curativa, Santiago, 5 de mayo de 1975, http://bcn.cl/27w3e

31 Givovic, Luis. 1973. "Salud Materno-Infantil”, Revista chilena de pediatría, 1973, vol. 44, №6, Santiago, p. 574. Disponible en línea en https://scielo.conicyt.cl/pdf/rcp/v44n6/art11.pdf
} 
en precarias condiciones" ${ }^{32}$. Es decir, el aborto no era una causal de penalización en caso de que fuese requerido y generado bajo condiciones de salubridad. Ejemplo de esta afirmación es que inclusive en hospitales como el Barros Luco se impartió un programa de inducción del aborto por Rivanol y raspado. Después, durante el régimen militar, gran parte de los médicos participantes de estos programas de anticoncepción fueron perseguidos, encarcelados y/o exiliados, ya que, según los mandatos autoritarios, atentaban contra la vida del que estaba por nacer ${ }^{33}$.

Entre septiembre de 1973 y 1990 se generaron una serie de transformaciones que en la cotidianeidad respondieron al nuevo rol que adoptó el Estado, otrora "benefactor". El objetivo fue la restauración del orden que había sido quebrantado con la Unidad Popular. Augusto Pinochet se instaló en el poder estableciendo una serie de redes que articularon el conservadurismo y el autoritarismo en el territorio: las Fuerzas Armadas y de Orden, Centros de Madres (entonces CEMA Chile), medios de comunicación oficialistas como El Mercurio, por mencionar algunas.

Respecto a la instauración de un nuevo orden en salud, Tetelboin y Salinas mencionan tres etapas claves entre 1973 y 1979: normalización, ofensiva de las propuestas privatizadoras y repliegue táctico de la ofensiva privatizadora. La reestructuración del Servicio Nacional de Salud corresponde a la etapa de normalización y restablecimiento del orden, siendo perseguidos quienes no lo acatasen ${ }^{34}$. Esto, para avanzar hacia una descentralización del sector salud pública y sus servicios. Como planteamos en la hipótesis de nuestra investigación, espacios como el Colegio Médico forman parte de la discusión sobre el rol del Estado respecto a la salud, existiendo tensiones sobre la salud centralizada en el SNS, al mismo tiempo que temores por los reajustes de recursos, que van desencadenando encuentros y desencuentros con la Junta Militar. Para la dictadura, tanto la nutrición como la planificación familiar fueron prioridades, sin embargo, ese interés no coincidía con el despliegue de la cartera correspondiente ${ }^{35}$.

La tasa de fecundidad existente durante la primera mitad del siglo XX en Chile comenzó a disminuir paulatinamente desde los años sesenta, pero firmemente desde los ochenta, sobre todo en las mujeres trabajadoras: "las mujeres activas tenían un promedio de 1,6 hijos por mujer en 1982 y 1992 (...); las mujeres inactivas tuvieron un nivel de fecundidad de 3,3 hijos por mujer en 1982; de 3,1 en 1992 y de 2,5 en 2002"36. En este análisis es importante destacar que la tendencia de mujeres trabajadoras con menos hijos es proporcional a las labores que

\footnotetext{
32 Jiles, Ximena y Rojas, Claudia.1992. De la Miel a los Implantes: Historia de las Políticas de Regulación de la Fecundidad en Chile. Santiago, Corporación de Salud y Políticas Sociales, 1992, p. 158.

33 Jiles, Ximena y Rojas, Claudia, De la Miel a los Implantes..., pp. 160-161.

${ }^{34}$ Tetelboin, Carolina y Salinas, Darío. 1984. "Estado y políticas de salud en Chile...", p. 360.

35 Ibídem, p. 382.

${ }^{36}$ Instituto Nacional de Estadísticas, Fecundidad en Chile, situación reciente, Santiago, Departamento de Estadísticas Demográficas, 2006, p. 10.
} 
desarrollan fuera y/o dentro del hogar. Una doble presencia que, como vimos en el apartado anterior, se manifiesta en ideales y roles asignados, y en donde las mujeres "inactivas" (dueñas de casa) siguieron aportando con hijos e hijas para la patria "refundada".

Ejemplo de lo anterior es el documento Política de población, de 1979, que promovió la moral y los roles tradicionales de hombres y mujeres en la familia, en lo privado y en lo público, de acuerdo con los valores estipulados por la religión y luego la Constitución de 1980. Los inicios de este documento de la Oficina de Planificación Nacional (ODEPLAN) señalan como pilares del "pueblo chileno" la moral cristiana y "esta visión trascendental del hombre, la fuente básica de donde emanan las principales directrices trazadas para lograr un efectivo desarrollo nacional $[\ldots]^{\prime \prime 37}$. La madre se constituyó como fundamental para la planificación familiar y para la moral y las buenas costumbres propuestas por la dictadura cívico-militar.

Reconociendo el potencial que existía en la movilización de mujeres, sobre todo de derecha, contra el gobierno de Salvador Allende, la Junta Militar de Gobierno anunció en 1974 la creación de la Secretaría Nacional de la Mujer (en adelante SNM), institución gubernamental encargada de transmitir el rol que les correspondía a las mujeres en lo que denominaba la Refundación Nacional y en el cual la maternidad ocupaba un lugar central.

Esto se realizó a través de diversos medios, especialmente a través de Revista Amiga, en la cual la SNM explicaba que su objetivo era "difundir los valores patrios y familiares, para formar en la mujer y en la familia una conciencia nacional y una correcta comprensión de su misión" ${ }^{38}$ y se agradecía a las mujeres en su lucha contra el marxismo porque "el hogar ha vuelto a la normalidad, la familia está unida; sus hijos ya no están marchando en las calles ni participando en huelgas" ${ }^{39}$. Precisamente es a raíz de lo anterior que se exaltó aún más la maternidad como gran responsabilidad social y ciudadana de las mujeres, quedando esto explicitado en los discursos dirigidos a ellas, en los que Augusto Pinochet afirmaba que:

“(...) no subestima por eso la labor anónima de las mujeres que trabajan en el laboratorio silencioso del hogar, velando por resguardar el más precioso capital de la nación: el cuidado de sus hijos, esperanza futura de la Patria. Por el contrario, creemos que es necesario hacer conciencia, en la propia mujer y en la sociedad entera, del valor de la tarea que a ésta le corresponde, y también de la dignidad inherente a su condición de tal” ${ }^{40}$.

\footnotetext{
37 ODEPLAN (Chile). 1978. Política de población: política poblacional aprobada por su excelencia el presidente de la República y publicada en el Plan Nacional Indicativo de Desarrollo: (1978-1983). Disponible en Memoria Chilena, Biblioteca Nacional de Chile http://www.memoriachilena.cl/602/w3-article-127284.html

${ }^{38}$ Revista Amiga, Año 1, n 10, noviembre de 1976, p. 7

${ }^{39}$ Revista Amiga, Año 1, n 4, mayo de 1976, p. 43

${ }^{40}$ La Junta de Gobierno se dirige a las mujeres de Chile, 24 de abril de 1974.
} 
De este modo, el papel de la mujer se construye directamente ligado con la política natalista del régimen. Con la penalización del aborto como ejemplo, se precisa lo que en la Política de Población era una categorización de la mujer como madre. El enfoque era la "superficialidad" con la que el "fenómeno cultural de la mujer como símbolo sexual" había repercutido en la relación madre-hijo. Más allá de la crítica que podamos hacer desde los debates de género para el análisis histórico, el documento apunta a que no hay otra dimensión para la mujer que ser madre ${ }^{41}$, ya que de esta forma el Estado asegura el "efectivo desarrollo nacional", directamente relacionado con el control de la población, o la reproducción para la producción, como una biopolítica de lo materno.

Las políticas familiares en dictadura están enfocadas principalmente a fortalecer los roles asignados de las familias en torno a los hijos, procurando apuntar al "desarrollo" sin considerar explícitamente las condiciones materiales de cada hogar, sino los pilares cristianos que sustentaron a la familia. Existió un desentendimiento del Estado neoliberal en estas materias, ya que en el documento se señaló explícitamente que "no es incumbencia del Estado el tomar medidas para lograr una disminución o aumento de la tasa de natalidad, más allá de la libre decisión del grupo familiar" ${ }^{42}$.

Esta libre decisión entiende a la familia en el espacio privado, cuestión que impacta no solo en las políticas de planificación familiar, sino también en el sistema de salud en tiempos de dictadura. Se reorganizó la salud pública y enfatizó "en torno a la naturaleza y características de un sistema nacional de servicios de salud, la descentralización funcional y geográfica de los servicios de salud $[. . .]^{\prime \prime 4}$.

Como bien se expone en los documentos, el SNS se fragmentó en 1979, generando así una nueva organización y administración de las políticas de salud pública, y un avance de la salud privada. En este punto nos preguntamos por el discurso médico presente en los Cuadernos médico-sociales en el marco de estas transformaciones, y en estrecha relación con lo que se divulga en la editorial y los artículos donde se aborda la realidad médico-social de las mujeres no solo en tanto madres, sino también en tanto campesinas del sur de Chile.

\section{Cuadernos médico-sociales: los orígenes de la defensa de la medicina social (1959-1973)}

Como ya se ha venido desarrollando, los Cuadernos médico-sociales tienen un origen posterior al Servicio Nacional de Salud (1952). La primera publicación data de junio de 1959. Al alero de seminarios de formación profesional médica, los Cuadernos médico-sociales pusieron desde

\footnotetext{
${ }^{41}$ ODEPLAN (Chile). 1978. Política de población: política poblacional aprobada por su excelencia el Presidente de la República y publicada en el Plan Nacional Indicativo de Desarrollo: (1978-1983), pp. 3 y 8 . Disponible en Memoria Chilena, Biblioteca Nacional de Chile http://www.memoriachilena.cl/602/w3-article-127284.html.

42 Ibídem, p. 7.

43 Raczynski, Dagmar.1980. "Reformas al sector salud: diálogos y debates”, Colección Estudios Cieplan, № 10, 198, Santiago, p. 10.
} 
sus orígenes el debate de la salud pública con las ciencias sociales, al alero del Colegio Médico, el Servicio Nacional de Salud y las Escuelas que impartían la enseñanza y aprendizaje de la medicina durante la época ${ }^{44}$. Es precisamente el argumento fundacional de los Cuadernos médico-sociales el que permite comprender la editorial permeada por el discurso interdisciplinar de la profesión médica, en relación con las comunidades, sobre todo de acuerdo con las condiciones del desarrollo profesional de los médicos, considerando que las realidades médicas eran también realidades sociales.

Respecto a los debates presentes entre médicos y profesionales de la salud en la década de los sesenta y los años de la Unidad Popular (1970 a 1973), nos encontramos con análisis inicialmente dirigidos a la formación de nuevos médicos, pero también ligados a la relación de la medicina con las comunidades y sus contextos particulares. Proliferan estudios vinculados al impacto de las políticas de planificación familiar desde las primeras publicaciones, sobre todo respecto a la realidad médico-social de distintos territorios de Chile y las experiencias de los médicos generales de zona, quienes después de ser formados en Escuelas de Medicina, postulaban y eran enviados a comunidades que requirieran de asistencia médica.

Entre su fundación y fines de 1961, las publicaciones estuvieron orientadas a la formación profesional de nuevas generaciones de médicos. Desde diciembre de 1961, este tipo de publicaciones son complementadas con análisis sobre la infancia, las familias, la nutrición y el desempeño del Servicio Nacional de Salud. A partir de 1967 se publicaron algunos artículos sobre la experiencia médico social en distintas partes de Chile, de sur a norte, principalmente rural (Achao, Frutillar, Los Vilos, Til-Til, Vicuña). Estas bitácoras presentaron planes de trabajo, propuestas de acción y acciones concertadas con las distintas comunidades y organizaciones de la época (Centros de Madres, Juntas de Vecinos, escuelas, etc.), y se replicaron, al menos hasta 1972:

“...se promovería la concientización del SNS y se organizaría la comunidad a nivel de salud utilizando las estructuras ya existentes [...] en las localidades de menor densidad de población propondríamos la formación de estaciones médico-rurales a cargo de una enfermera, una matrona y dos auxiliares, quienes la visitarían mensualmente" ${ }^{45}$.

En años anteriores se presentaron orientaciones generales respecto al rol de las madres en la crianza. En la comuna de Los Lagos (actual región de Los Ríos), principalmente rural, dos médicos y una asistente social analizan la educación materna y la desnutrición infantil. Entre las características de la investigación se encuentra la revisión de los hábitos alimentarios de las madres en relación con los recién nacidos, críticas al "destete" temprano, al uso de alimentos

\footnotetext{
${ }^{44}$ Cuadernos médico-sociales. 1959. Publicación oficial de la Comisión Organizadora, Santiago de Chile, № 1.

45 Vásquez Homero. 1971. “Experiencia de un médico general de zona en el hospital de Quellón, Chiloé (años 1966 1970)", Cuadernos médico-sociales, vol. XII, № 1, Santiago, p. 19.
} 
no nutritivos como reemplazo de la leche, y las condiciones de vida de las mujeres. El estudio concluye apelando a la necesidad de recursos que sostengan la educación y el respaldo material de estas familias, al mismo tiempo que las voluntades de los profesionales de salud para llevar adelante estas acciones educativas ${ }^{46}$. El estudio reconoce las dificultades y falta de acceso a información por parte de estas mujeres (madres solteras, analfabetas, de escasos recursos), y el impacto en la crianza.

Asimismo, también encontramos publicaciones sobre planificación familiar y la relación con los hombres ${ }^{47}$. Estos trabajos ya venían desarrollándose desde 1964, aunque con irregularidad y con precisiones más generales, sin que se ignore el rol de las mujeres en las crianzas. En los años setenta se retomaron algunos estudios de casos, situados en la experiencia de centros de salud rurales, vinculando las condiciones materiales, de educación formal y de vida con el acceso o uso de anticonceptivos ${ }^{48}$, o con la realidad médico-social de espacios rurales, las condiciones de atención y propuestas de solución a los problemas consignados, asumiendo lo que señalan como una lucha contra la pobreza y el subdesarrollo.

Sobre lo anterior, es interesante el correlato con el rol de los médicos generales de zona (MGZ), ya que de acuerdo con publicaciones que analizan sus percepciones en torno al trabajo en provincias, aparece como principal razón estar cumpliendo una importante función social en espacios en donde escasean los recursos materiales y humanos ${ }^{49}$. Esto se vincula con la revisión que posteriormente se hace de los Internados Rurales para médicos, para fomentar el carácter público y comprometido con la comunidad de los profesionales de la salud, cuestión que como planteamos al inicio, es motivo de tensión y expresa la heterogeneidad de profesionales dentro del mismo Colegio Médico, ya que la dictadura cívico-militar transforma la relación entre la burocracia estatal y la salud, desencadenando su privatización hacia los años ochenta.

Precisamente, antes del golpe de Estado, en Cuadernos médico-sociales hay debates en torno a la salud pública y su relación con la maternidad en los hospitales, sobre las metas pendientes para la época, principalmente en la formación y conciencia de los equipos de salud sobre la planificación familiar, anticoncepción y promoción de la higiene en madres e hijos: "cuando la responsabilidad de la salud sea colectiva y el diálogo médico-cliente, además de "clínico" sea reemplazado por el diálogo comunidad-individuo-equipos de salud, para oír,

\footnotetext{
${ }^{46}$ Soto, Rebeca., Rodríguez, Héctor., González, Luis.,. 1969. "La educación materna en la desnutrición infantil en un área rural", Cuadernos médico-sociales, Vol. X, №2, Santiago, pp. 24-27.

47 Hall, Francoise.1969. "Los hombres, la anticoncepción y el aborto", Cuadernos médico-sociales, Vol. X, n², septiembre 1969, pp. 14-23.

48 Plank, Stephen y Milanesi, María. 1970. "Características demográficas y planificación familiar en áreas rurales de Chile", Vol. XI, № 3, pp. 42-49.

49 Díaz, Ximena. 1972."El Médico General de Zona: Imágenes de su trabajo, valores ocupacionales y estudio de satisfacción profesional”, Cuadernos médico-sociales, Vol. XIII, p. 5.
} 
prescribir, aconsejar y desarrollar conductas y responsabilidades para vivir en salud y seguridad, los Ilamaremos Centros de Salud" 50 .

Como se señaló en el apartado teórico, el Estado debe administrar el cuerpo de las mujeres en favor del cuerpo de la nación, ya que es en la nación donde los nacimientos se vinculan dentro de los límites territoriales del Estado, protegiendo la vida colectiva de esta unidad parental/territorial/política de todo aquello que la niega o la pone en peligro, aplicando un "sentido inmunitario nacional por el medio del cual se construye al otro como elemento patógeno que se debe exterminar para mantener el cuerpo sano de la nación" ${ }^{51}$. Un sentido que funciona a través del agente médico, activo no solo en los hospitales o como generales de zona, sino también a través de la difusión de sus experiencias y análisis académicos, en los Cuadernos médico-sociales. En estas publicaciones se expresaron diagnósticos que incorporaron defensas o críticas a la ejecución ministerial o del Servicio Nacional de Salud, reconociendo o proponiendo estrategias a los gobiernos de turno. Podemos evidenciar lo anterior cuando se analizan hitos como el Plan Nacional de Leche (1971), y sus implicancias frente a los problemas nutricionales y el ideal de los niños sanos, con énfasis en la educación alimentaria de las madres, fortaleciendo el binomio madre-hijo: "La leche es necesaria en toda edad, pero de preferencia deben consumirla los niños, las embarazadas y las madres que amamantan" ${ }^{22}$.

El rol del SNS en el marco de este plan es consignado por los Cuadernos Médico-Sociales, sobre todo en las proporciones de cobertura, el despliegue del voluntariado, como también las condicionantes para la época, tanto a nivel de gestión de recursos como de recepción del programa, con respuestas elaboradas desde datos y análisis de las preguntas frecuentes, alentando y respaldando la iniciativa ${ }^{53}$. Frente a eso, nos encontramos con un despliegue comunicacional como el divulgado en los famosos afiches de la Polla Chilena de Beneficencia, que entre 1971 y 1973 promovieron en sus dibujos no solo la relevancia del Plan Nacional de Leche, sino también la educación en higiene sanitaria y la importancia de la salud pública:

\footnotetext{
${ }^{50}$ Adriasola, Guillermo. 1972. "Higiene materna e infantil en Chile", Cuadernos médico-sociales, vol. XIII, n 1, marzo 1972, p. 40.

51 Arcos, Carol. 2018. “Feminismos...", p. 37.

52 Programa Nacional de la Leche (Servicio Nacional de Salud). 1972. Alimentación complementaria: esfuerzo de todo el pueblo. Instructivo para personas que participan en labores educativas. Santiago, Imprenta Central de Talleres SNS.

53 Solimano, Giorgio; Unda, Hugo y Álvarez, Alfonso. 1972. "Programa Nacional de Leche”, Cuadernos médicosociales, vol. XIII, № 4, Santiago.
} 


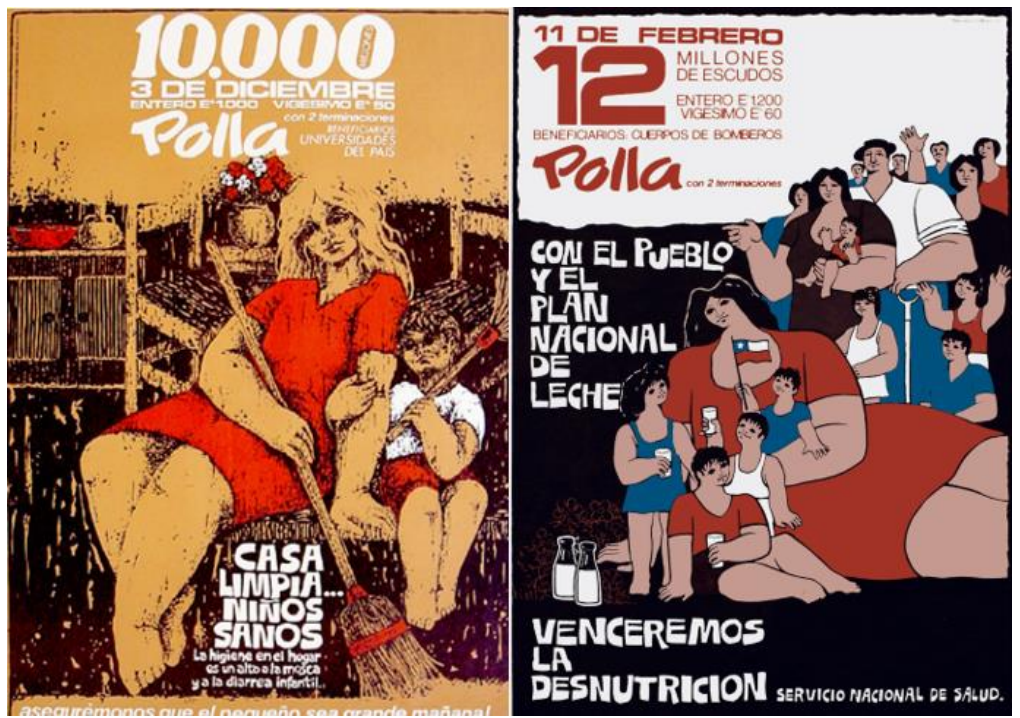

Figura 1: Afiches "Polla chilena de Beneficencia", 3 de diciembre 1972 y 11 de febrero 1973, respectivamente.

El quiebre democrático transformó definitivamente el papel de la salud pública. El golpe de estado el 11 de septiembre de 1973 no fue parte de la nota editorial ni parte de los titulares de artículos que devinieron en Cuadernos médico-sociales. Sin embargo, paulatinamente nos encontraremos con elementos de continuidad y cambio, sobre todo ligado a la salud pública y la relación de esta con la maternidad rural y pobre.

El impacto de la dictadura en la salud pública nacional ¿Qué evidencian los Cuadernos médico- sociales? (1973-1983)

Como se ha señalado, dado que los Cuadernos médico-sociales se desprenden del Colegio Médico, es necesario plantearnos el rol de este organismo respecto al Servicio Nacional de Salud. Hubo críticas a un sistema único de salud, pero también discrepancias de carácter económico entre el Colegio Médico y el régimen, sobre todo en lo que fue el traspaso de profesionales del sector público al privado, según la prensa de la época y los análisis desarrollados. Los mismos artículos de Cuadernos médico-sociales revisados hasta acá (y escritos antes del golpe de Estado) revelan una defensa de la medicina social, encarnada sobre todo en los Médicos Generales de Zona (MGZ) que proliferaron por poblados apartados del territorio chileno.

Tetelboin y Salinas señalan que no existió un distanciamiento considerable entre el Colegio Médico y la Junta Militar, sino una posterior ofensiva de reestructuración que generó un 
despliegue de cooperativas de salud privadas, la creación de un Fondo Nacional de Salud (FONASA), el Instituto de Salud Pública, y la Central Nacional de Abastecimientos del Sistema Nacional de Servicios de Salud ${ }^{54}$. Para ese mismo año de promulgación, el Colegio Médico expresó su respaldo a la medicina social, "rechazando los principios de subsidiariedad del Estado y los criterios 'economistas'"155 del decreto 2.763, que reestructuró la salud pública en Chile. En este punto nos preguntamos cómo esta reestructuración impactó en los discursos específicos presentes en las publicaciones de los Cuadernos médico-sociales, sobre todo cuando se dirigieron a madres campesinas del sur de Chile, y no perdiendo de vista los mandatos familiares que se venían gestando desde décadas de moral cristiana, y fueron fortalecidos con la dictadura cívico militar.

Al revisar los Cuadernos médico-Sociales, uno de los aspectos en donde se liga la atención médica con la ruralidad son las visitas domiciliarias. Según los datos analizados en los anuarios estadísticos de atenciones y recursos del Ministerio de Salud, aparecen los indicadores de la relevancia que tuvieron profesionales de salud como enfermeras, matronas, nutricionistas y auxiliares paramédicos en el sur de Chile a través de estas visitas a los domicilios, aun cuando los datos no especifican las diferencias entre urbanidad y ruralidad. A partir de los datos publicados por el Ministerio de Salud, hay al menos dos elementos interesantes para desarrollar el análisis.

Gráfico 1: Visitas domiciliarias de matronas, enfermeras y auxiliares paramédicos en el sur de Chile (1973-1984)

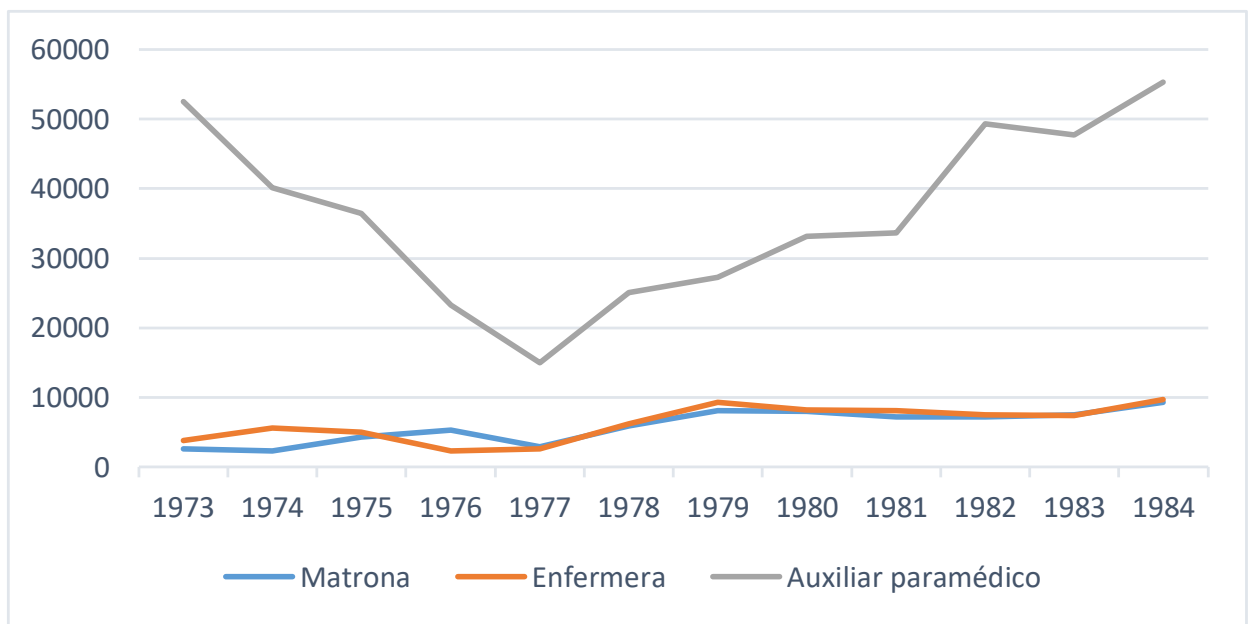

Elaborado por las autoras. Fuente: Anuarios de Atenciones y Recursos, 1973-1984, Ministerio de Salud, Chile.

\footnotetext{
${ }^{54}$ Ministerio de Salud Pública, Decreto ley n².763, Diario Oficial, 03 de agosto de 1979, pp. 1-2

55 Tetelboin, Carolina y Salinas, Darío. 1984., "Estado y políticas de salud en Chile: el proceso de...", p. 382.
} 
Hasta el año 1977, los anuarios de atenciones y recursos registraron las visitas domiciliarias sin diferencias entre Servicio Nacional de Salud (SNS) de otros espacios como el Servicio Médico Nacional de Empleados (SERMENA) ${ }^{56}$. Desde 1978 se clasificaron las atenciones de cada espacio, se separaron las visitas domiciliarias de especialistas (médicos, matronas y enfermeras) dirigidas a adultos y a niños, mientras que las visitas domiciliarias de auxiliares paramédicos se separaron entre visitas a mujeres y visitas a adultos. Además, desde 1979 comenzaron a contabilizarse las visitas domiciliarias de nutricionistas y ya no se registraron las visitas domiciliarias de médicos.

El Gráfico 1 muestra cómo fluctuaron las visitas domiciliarias, considerando que entre 1978 y 1980 los datos señalan que la mayoría de estas estaban dirigidas a niños. Mientras, en los datos de fines de los años setenta, se diferencian las estadísticas de visitas domiciliarias cuando estas fueron hechas por enfermeras y auxiliares paramédicos (Gráficos 2 y 3 ).

Gráfico 2: Visitas domiciliarias enfermeras en el sur de Chile (1978-1979).

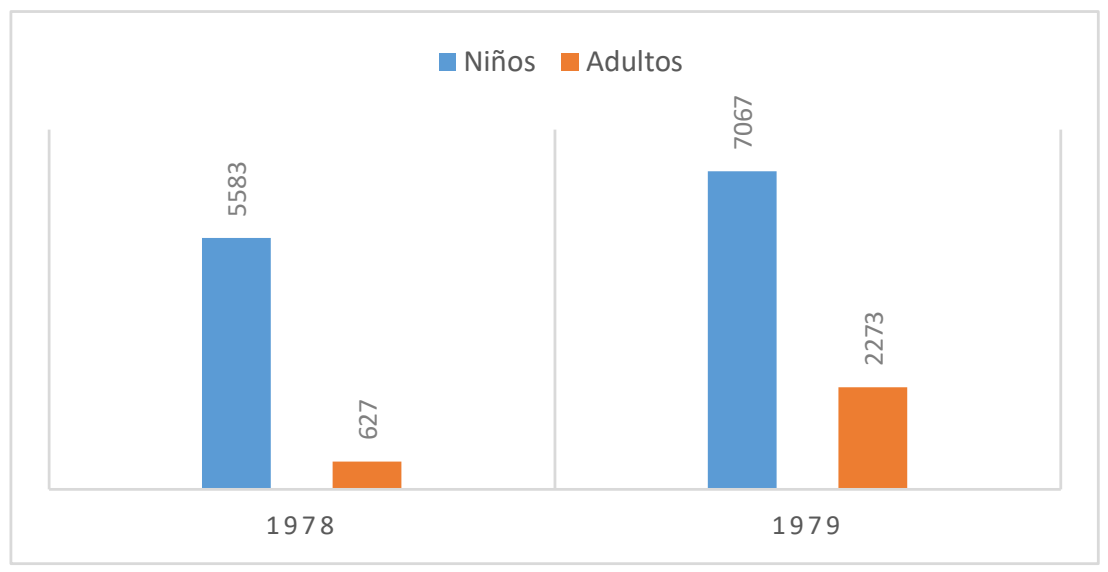

Elaborado por las autoras. Fuente: Anuarios de Atenciones y Recursos, 1973-1984, Ministerio de Salud, Chile.

No es casual que se haga énfasis en la atención médica a la infancia en esos dos años, sobre todo considerando que el año 1979 se celebró el Año Internacional del Niño. En los Cuadernos médico-sociales hay un énfasis en la nutrición infantil desde las publicaciones de la década de los sesenta, como analizamos en el apartado anterior. Esto continúa desarrollándose en las publicaciones posteriores, sin embargo, desde diciembre de 1973, paulatinamente encontramos que hay menos menciones a regiones y se generalizan los estudios de caso,

\footnotetext{
${ }^{56}$ Según consigna la página del Ministerio de Salud, "en 1979 se fusionan el SNS y SERMENA, con lo cual se reorganiza el Ministerio de Salud. Se crean los Servicios de Salud, el Fondo Nacional de Salud (Fonasa), la Central Nacional de Abastecimiento (Cenabast) y el Instituto de Salud Pública (ISP). La nueva institucionalidad permite el acceso a beneficios al sistema de libre elección". Recuperado de https://www.minsal.cl/hitos-de-la-salud-chilena/
} 
restringidos al centro político-administrativo y a lo urbano. Creemos que esto es relevante porque permite develar el rol del agente médico en este proceso, y las concepciones sobre las mujeres rurales como sujetas.

Gráfico $N^{\circ} 3$ : Visitas domiciliarias auxiliares paramédicos en el sur de Chile (1978-1979)

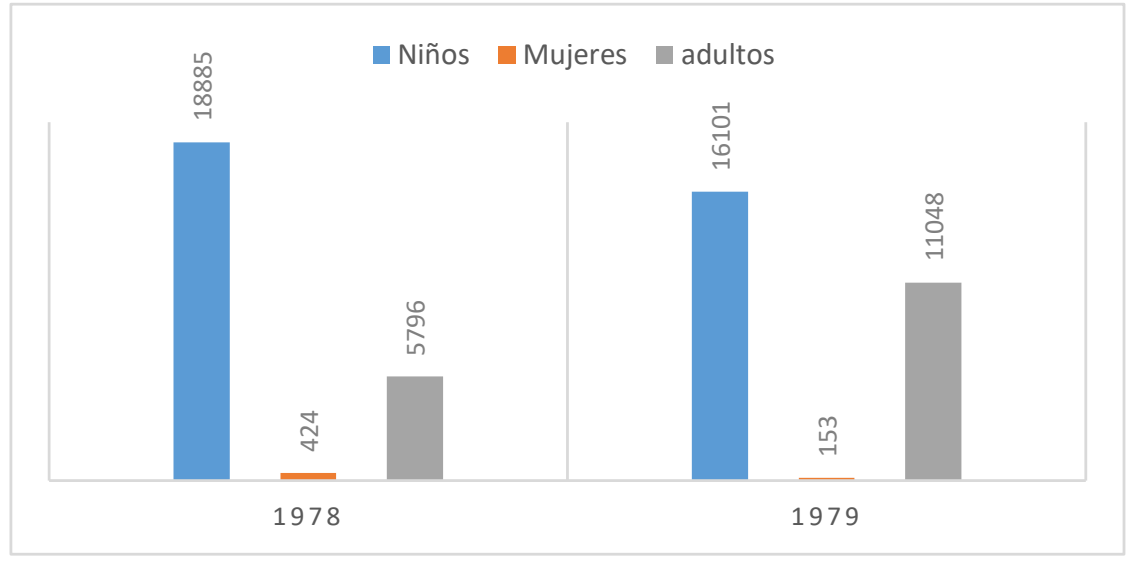

Elaborado por las autoras. Fuente: Anuarios de Atenciones y Recursos, 1978-1979, Ministerio de Salud, Chile.

\section{Los Cuadernos médico-sociales en dictadura y las madres rurales. Continuidades y cambios desde los saberes expertos (1973-1983)}

Si bien encontramos variadas publicaciones dirigidas a la maternidad o a la relación entre las madres y la salud de niños y niñas, son escasas las orientaciones estrictamente dirigidas a las madres rurales, por lo que en este apartado desarrollamos análisis a partir de los silencios de la documentación revisada.

De las últimas publicaciones dirigidas a difundir la experiencia de los equipos médicos zonales, encontramos una referencia a tres años de labores de salud en Panguipulli, hacia la precordillera valdiviana. En ese artículo el médico diagnosticó las dificultades de acceso y comunicación en el sector, que hasta 1974 describió como predominantemente rural. Asimismo, se expuso el déficit en recursos e infraestructura de atención en las distintas postas que rodeaban a Panguipulli, además de la escasez de profesionales para la atención y cómo esto se fue solucionando: "gran multiparidad, enfermedades carenciales, anemias ferroprivas, altos índices de partos prematuros y desnutrición materna" ${ }^{57}$. Hasta 1973 solo había una matrona "religiosa", dada la existencia de un hospital misional en Panguipulli. Para el médico y el equipo de salud que escribió el artículo, uno de los principales problemas de salud en torno

\footnotetext{
57 Irribarra, Néstor, "Panguipulli. Tres años de Labor en salud", Cuadernos médico-sociales, vol. XV, $\mathrm{n}^{\circ} 4$, diciembre 1974, p. 19.
} 
a las mujeres rurales de la zona era "a) falta de conocimiento en torno a una paternidad responsable b) ruralidad y falta de medios de transporte para acudir a los controles $c$ ) machismo imperante d) falta de medicamentos e) bajo nivel económico" ${ }^{58}$. En el documento referenciado se ignora la pertenencia étnica de las personas que se atendían en el hospital misional, sin embargo, es una variable que complejiza el estudio de la ruralidad y el género. Lo que sí es común es que se correlaciona la ruralidad con la pobreza, desde un saber experto que reflexiona esa vinculación a partir de las carencias materiales. Respecto a lo sanitario, nuevamente, como en los análisis de años anteriores, aparece el problema de la desnutrición infantil, con una reflexión en torno al exacerbado porcentaje de mortalidad infantil en Panguipulli (240\% a 1972), y la insistencia frente al abandono de la salud pública en estos espacios rurales.

Es interesante consignar que al final del escrito, quienes escriben señalan que su rol como profesionales de la salud está con los más desfavorecidos y marginados, reconociendo en Panguipulli uno de los sectores más azotados por los cambios políticos, económicos y sociales de la época. Esta sutil referencia al golpe de Estado y lo que significó para la precordillera valdiviana es una muestra del posicionamiento autónomo de los médicos colegiados o profesionales de la salud respecto al quiebre democrático y sus impactos. Es un estudio escrito un año después del cierre del Complejo Maderero Panguipulli y de la persecución y matanza de decenas de obreros madereros y campesinos de la región cordillerana, y que permite establecer la heterogeneidad al interior de un gremio que, como vimos en los análisis de Tetelboin y Salinas, se expresa en la defensa o desconocimiento de la medicina social.

Algunos artículos referidos a la alimentación infantil y el rol de la lactancia materna siguen circulando, recogiendo estudios de mujeres hospitalizadas, sus condiciones de vida y cómo se relacionan con sus hijos los primeros días de vida, la desnutrición y los destetes precoces (asociados a madres jóvenes entre 15 y 23 años, principalmente solteras) como un factor de las modificaciones en la alimentación a los recién nacidos. Las matronas y docentes de Obstetricia de la Universidad de Chile desarrollan este estudio planteándose las dificultades de entender y definir la maternidad como una categoría estática, para plantearse nuevos aportes en las mallas de formación de matronas y matrones: "Los roles maternos de procreación, de lactancia, de socialización primaria son reiterativos en todas las sociedades, en las generaciones y en todas las culturas y parecen no ser alterados. Sin embargo [...] ciertas variaciones se dan en la lactancia natural" ${ }^{59}$.

Al igual que en sus inicios, existen artículos que persisten en el interés por la formación de los profesionales de salud (sobre todo los médicos), en la educación que deben recibir estos

\footnotetext{
58 Ibídem, p. 21.

59 López, Ilse, Alvarado, Elisa, Arcuch, Sara, Cabiol, Carmen y Rivera, Eliana. 1974. "Duración de la Lactancia Materna y algunos Factores condicionantes", Cuadernos médico-sociales, Vol. XV, № 4, p. 13.
} 
para poder educar a su vez a la población, diagnosticando la cobertura y las estadísticas de Chile respecto a otros países en la década de los setenta, por ejemplo. Las publicaciones dedicadas a la experiencia docente en internado rural en 1976, o cómo funcionan las postas rurales en 1983 son los únicos acercamientos explícitos que encontramos en los Cuadernos médico-sociales a las madres rurales.

También podemos encontrar estudios que analizan cómo se fue controlando la mortalidad de recién nacidos, a pesar de persistir altas tasas en relación con el promedio en provincias del sur de Chile. Entre los factores, se indican los volúmenes de atención profesional de los partos y las condiciones de vida de las madres (si fueron madres precoces, menores de 20 años; mayores de 30 años, analfabetas, con educación formal incompleta o baja; y madres que controlan su embarazo tardíamente en los servicios de salud, o controlan tarde a sus recién nacidos $)^{60}$. Sobre esto último, se enfatiza en la atención no profesional en los partos, o los partos en casa, y cómo estos influyeron en la mortalidad perinatal y neonatal. A partir de testimonios de mujeres de la época, los partos en casa se concentraron en espacios rurales o donde existían dificultades geográficas para acceder a centros de salud u hospitales, por lo que más allá de existir una crítica a las mujeres, se denunció la falta de preocupación e ineficiencia del Ministerio de Salud de la época:

"La mortalidad neonatal muestra en Chile un ascenso en los meses fríos que en 1973 fue del orden del $20 \%$. Este exceso de mortalidad se atribuye al mayor riesgo de los niños de bajo peso de nacimiento en estos meses; a las dificultades de atención materna que surgen en las zonas rurales durante el invierno y a variaciones estacionales de algunas patologías" ${ }^{61}$.

A diferencia de los años anteriores, vemos publicaciones donde las referencias a lo rural están orientadas al centro político administrativo. Ejemplo de esto son artículos con los casos de Los Andes y Cauquenes, donde se aborda el internado rural de estudiantes de medicina, y la importancia de esa instancia en la formación de médicos comprometidos con la salud pública y los diversos contextos socioculturales ${ }^{62}$. Asimismo, los trabajos que exponen el rol de las postas rurales para la salud pública de las provincias, planteadas como esenciales para la atención primaria en localidades rurales:

"Atiende núcleos pequeños de población y sus funciones están destinadas especialmente al fomento y protección de la salud en forma continua desarrollando una interrelación

\footnotetext{
${ }^{60}$ Kaempffer, Ana María, Medina, Eduardo., De la Fuente María y Romero María. 1976, "Los problemas de salud del Recién Nacido en Chile", Cuadernos médico-sociales, Vol. XVII, Santiago, p. 7.

61 Ibídem, p. 7.

62 De la Fuente, María. y Albala, Cecilia. 1977., "El internado rural como experiencia docente en la Facultad de Medicina sede Norte", Cuadernos médico-sociales, vol. XVIII, n³, Santiago, pp. 30-38.
} 
permanente con la comunidad. El auxiliar de salud constituye el elemento central para el logro de los objetivos de este nivel de atención" ${ }^{63}$.

Al desarrollar una comparación entre las regiones analizadas, los autores del artículo señalan que las postas rurales de la región de Los Lagos, en el sur de Chile, son "las más desprovistas en la implementación necesaria para cumplir con los objetivos establecidos por cuanto sólo reúnen en promedio $47,2 \%$ de los requisitos considerados como óptimo. Este resultado las ubica en un nivel francamente deficiente" ${ }^{64}$. En esa misma línea, se critica el apoyo a nivel central y la ineficiencia del Ministerio de Salud, ya que hay elementos que no son supervisados o aplicados en las postas rurales, como por ejemplo los controles de niño sano, controles prenatales o de puerperio. Asimismo, encontramos estudios cuantitativos y cualitativos que analizan los partos de mujeres que no fueron atendidas por profesionales en diversas localidades de otras provincias, o que registraron tarde a sus hijos e hijas, siendo el origen rural y la conectividad uno de los factores que justificarían las situaciones ${ }^{65}$.

A pesar del menor énfasis en las provincias o en lo rural, persistieron los estudios dirigidos a las mujeres como madres, los vínculos infanto-maternos en tanto "deber ser", o el impacto en la desnutrición infantil considerando la experiencia de estas madres cuando fueron niñas: "si las primeras relaciones objetales de la madre cuando niña han sido predominantemente negativas, el proceso de la identificación será interferido. Ello incidirá directamente en la femineidad alterando de diversas maneras la función procreativa y la maternidad en general [...] lo que producirá fuertes sentimientos rechazantes y agresivos hacia el hijo"66. El supuesto teórico que fue comprobado en esta investigación era que "en las madres de desnutridos la maternidad no cumpliría su función de etapa de crecimiento pues en ellas habría impedimentos sicológicos de personalidad que las llevaría a establecer una relación afectiva madre-hijo insatisfactoria" ${ }^{\prime 67}$. Al mismo tiempo, luego de confirmar la importancia de la relación madre-hija en la infancia, y a propósito de uno de los criterios de selección de las mujeres, muchas de ellas además eran madres de hijos "no deseados", y con historiales de abuso de alcohol y violencia, lo que también muestra los posicionamientos desde algunos profesionales de la salud y los saberes que propulsan y naturalizan algunos mandatos familiares reforzados con la dictadura cívico-militar, como la criminalización de la pobreza en los contextos urbanos.

\footnotetext{
${ }^{63}$ Borgoño, José; Chang, Nelly; Aldea, Amparo y Acuña, Claudio. 1983, "Condiciones de eficiencia de las Postas Rurales", Cuadernos médico-sociales, vol. XXIV, № 1, Santiago, p. 24.

64 Ibídem, p. 25.

65 Villagran, Germán y Candia, María. 1982. "Algunos factores que influyen en el inadecuado Registro de Partos sin atención Profesional”, Cuadernos médico.sociales, vol. XXIII, Santiago, p. 18.

${ }^{66}$ Kartzow, Myrella. 1978. "Algunos aspectos Psicológicos Maternos en la Desnutrición Infantil”, Cuadernos médicosociales, Vol. XIX, 4, Santiago, p. 15.

67 Ibídem, p. 16.
} 
Los estudios sobre la lactancia continuaron homologando el rol de la madre al de otros mamíferos, pensando en la existencia de nuevos vínculos madre-hijo y la amenaza "del desarrollo cualitativo de la vida humana"68. Al menos esta última idea la encontramos en estudios anteriores sobre lactancia, destete precoz, pero sin tanto detalle respecto al rol de la madre o de los equipos de salud en la educación. Por ejemplo, se explicita sobre las madres solteras, homologadas como mujeres con situación de alto riesgo: "es de mayor riesgo la madre soltera o que convive en forma irregular con su pareja. Aun cuando los factores biodemográficos, socioeconómicos y sociológicos ya nombrados no son estrictamente causales ni modificables por el equipo de salud, es importante que éste los considere" ${ }^{\prime \prime}$.

Otras publicaciones que prevalecen, al menos hasta el período de estudio abarcado en esta investigación, son los análisis a los equipos de salud, al buen o mal funcionamiento de algunos centros asistenciales en espacios periféricos o con mayor demanda, sobre todo en la atención materno-infantil: "si se quiere mejorar la atención primaria en el campo materno-infantil, que tiene alta prioridad de acuerdo con la política de Gobierno, requiere que este compromiso se refleje en una adecuada distribución de los recursos y en mejorar substancialmente las condiciones de trabajo de ese nivel" ${ }^{\prime 70}$. Estas críticas a las deficiencias con las que atienden los centros de salud las encontramos implícita o explícitamente, como en este último caso, y nos advierten de una continuidad en el rol de los Cuadernos médico-sociales en aspecto divulgador científico-social crítico y la defensa de la medicina social.

Es interesante consignar que para fines de los años setenta los anuarios de atención comenzaron a contabilizar las visitas domiciliarias de nutricionistas, además de los otros profesionales que están registrados desde la década de los sesenta, donde no existieron fluctuaciones significativas o muy diferenciadas más allá de su aparición. Desde 1985 no se contemplan visitas domiciliarias en los registros, solo consultas y atenciones que no son tipificadas como en los anuarios anteriores, solo generalizadas. Lo que sí encontramos es que, desde 1978 y a nivel nacional, se tipificaron los controles a mujeres y niños por médicos y por matronas, específicamente (ver Cuadro 1):

\footnotetext{
${ }^{68}$ Mardones, Francisco.1980, "Una estrategia educativa para el fomento de la lactancia materna” vol. XXI, Santiago, p. 97.

69 Pereda Cristian y Rodríguez Jeremimah.1982. “Diagnóstico de situación de la lactancia materna en cuatro regiones de salud de Chile-1979", Cuadernos médico-sociales, Vol. XXIII, №1, Santiago, p. 22.

70 Borgoño José; Chang Nelly; Aldea Amparo y Acuña Claudio. 1983. "Condiciones de eficiencia de las Postas Rurales", Cuadernos médico-sociales, vol. XXIV, Santiago, p. 24.
} 
Cuadro 1: Atenciones de médicos y matronas dirigidas a niños y mujeres a nivel nacional, 1978-1990

\begin{tabular}{|c|c|c|c|c|}
\hline & \multicolumn{2}{|c|}{ Médicos } & \multicolumn{2}{c|}{ Matronas } \\
\hline Año de atención & Controles a niños & $\begin{array}{c}\text { Controles } a \\
\text { mujeres }\end{array}$ & $\begin{array}{c}\text { Control a recién } \\
\text { nacido y lactancia } \\
\text { materna }\end{array}$ & Controles a mujeres \\
\hline 1978 & 201.802 & 165.450 & 96.572 & 2.526 .037 \\
\hline 1979 & 227.505 & 168.826 & 79.617 & 2.664 .011 \\
\hline 1980 & 278.470 & 206.474 & 80.817 & 2.853 .480 \\
\hline 1981 & 272.062 & 209.376 & 96.802 & 2.998 .617 \\
\hline 1982 & 329.929 & 234.935 & 96.973 & 3.263 .441 \\
\hline 1983 & 348.228 & 257.592 & 91.623 & 3.351 .546 \\
\hline 1984 & 378.849 & 270.076 & 91.329 & 3.133 .782 \\
\hline 1985 & 406.165 & 289.348 & 88.893 & 3.511 .996 \\
\hline 1986 & 428.260 & 283.899 & 91.741 & 3.554 .227 \\
\hline 1987 & 458.301 & 281.014 & 93.966 & 3.586 .878 \\
\hline 1988 & 504.275 & 283.596 & 102.584 & 3.845 .906 \\
\hline 1989 & 528.387 & 277.172 & 99.833 & 3.959 .526 \\
\hline 1990 & 538.464 & 277.748 & 104.327 & 4.041 .044 \\
\hline
\end{tabular}

Elaborado por las autoras. Estadísticas e indicadores de atención en Chile 1978-1998, Ministerio de Salud, Chile.

Al mismo tiempo que la diferencia cuantitativa en atención de médicos y matronas dirigida a mujeres y a niños es amplia, estas gráficas nos permiten entender el énfasis en los controles de salud a mujeres y recién nacidos, pensando en las formaciones de cada especialista, pero también en cómo crecen, decrecen o persisten los números en las atenciones de mujeres y niños durante la década de los ochenta. Si bien la tabla anterior es una muestra a nivel nacional, podemos inferir el vínculo entre mujeres y centros de salud, y establecer un panorama de la relación priorizada de atenciones de los médicos respecto a las matronas, cuestión que de una $\mathrm{u}$ otra forma se ve reflejada en las publicaciones de los Cuadernos médico-sociales, donde las referencias a la mujer en tanto madre como mandato familiar fue una constante analítica. Esto persistió independiente del posicionamiento del agente médico respecto a la medicina social.

\section{Conclusiones}

Si bien la preocupación por la salud materno-infantil tan presente para las autoridades tanto políticas como médicas durante la mayor parte del siglo XX chileno continuó durante la dictadura cívico-militar, parece evidente la ruptura existente entre la centralidad y la importancia que había adquirido la salud pública hasta el gobierno de la Unidad Popular y la transformación burocrática y privatizadora que experimenta luego de 1973. 
Es posible afirmar, a partir de los Cuadernos médico-sociales, que antes y durante la dictadura cívico-militar, persiste un discurso biomédico que releva el rol de la madre y el vínculo infanto-materno a nivel sanitario. Se continúa haciendo hincapié, sobre todo, en la importancia al deber ser de la mujer como madre, a partir de estudios sobre lactancia materna, o la relación entre la crianza materna y la nutrición infantil. Sin embargo, podemos distinguir cierta autonomía y posiciones críticas respecto al Estado autoritario y el abordaje de la salud pública, lo que responde al carácter del Colegio Médico como espacio habitado por médicos con heterogéneo posicionamiento político y social.

En esta misma línea, se mencionan las deficiencias en la salud infanto-materna en la ruralidad del sur de Chile y se explicitan causas relacionadas a la pobreza y la falta de conectividad para acceder a la atención de sanidad, donde se interpela al Estado autoritario como responsable de la gestión en salud. Aun así, las madres campesinas aparecen mínimamente y en un discurso generalizado en las distintas entregas de los Cuadernos médicosociales, que progresivamente dejan de realizar análisis entre maternidad provincial, urbana y rural para centrarse en un análisis nacional de la realidad de la salud infanto-materna. Nos aventuramos a explicar esta situación por el propósito homogeneizador del proyecto de "Refundación Nacional" de la dictadura cívico-militar en concordancia con sus metas de desarrollo económico, poniendo su atención en el centro geopolítico del país, es decir, la Región Metropolitana y sus alrededores, y desde allí, uniformando la realidad nacional frente a análisis y estadísticas internacionales, en correlato con la progresiva urbanización en detrimento de la ruralidad. Recordemos que, en el marco de la Guerra Fría, Chile estaba bajo escrutinio internacional siendo el primer país en el que se ponía en práctica el neoliberalismo, modelo que el régimen militar -y también sus integrantes civiles, como los Chicago Boys- necesitaban validar frente al mundo y, por lo tanto, comprobar que la función de lo público no era primordial para el bienestar de la población.

Es posible identificar en las políticas de salud materno-infantil y los discursos en los Cuadernos médico-sociales el modelo de familia tradicional que desde ese pilar ideológico se promovió como el discurso de género uniformador dirigido a las mujeres, lo que evidencia el objetivo del régimen de restituir el orden social imperante antes del proceso de democratización que se había desarrollado en las décadas previas. Por ejemplo, en la crítica presente a las madres solteras o hacia aquellas que no se encuentran casadas con sus parejas y/o padres del menor, equiparándolas a maternidades de alto riesgo y responsabilizándolas, por lo tanto, de la posible inestabilidad en el estado de salud de sus hijos, desestimando otros factores como la pobreza, el territorio, las desigualdades estructurales entre diferentes zonas del país y su infraestructura. Si pensamos estos mandatos de género durante la dictadura atravesados por la moral cristiana para el proyecto de familia del régimen, es menos explícito, 
pero sí latente en tanto se piensa en la mujer casada como sujeta menos vulnerable y más responsable en la alimentación de sus hijos.

Esto no quiere decir que el Colegio Médico no tenga diferencias con la dictadura cívicomilitar, ya que, como vimos, se explicitan denuncias frente al abandono y falta de recursos en salud sobre todo en sectores rurales o marginales en lo urbano. Ha sido posible encontrar discursos en algunas publicaciones donde algunos y algunas profesionales de la salud denunciaban la falta de preocupación e ineficiencia del Ministerio de Salud en la realidad rural y las desigualdades socioeconómicas y geográficas de su población, transparentando las consecuencias de la ausencia del Estado, siendo un ejemplo clarificador de su nueva labor subsidiaria. Estas denuncias son relevantes sobre todo si se tiene en consideración el contexto de violencia y represión hacia toda persona que se posicionó en contra de las autoridades de gobierno, lo que refleja cierta independencia, aunque sutil, del Colegio Médico frente al Ministerio de Salud, y las tensiones y disputas en torno al proyecto de salud pública y rol profesional de los médicos.

Como el nombre de la revista lo indica, y tal como se explicitó durante el cuerpo del artículo, la fundación de los Cuadernos médico-sociales tienen un correlato con el despliegue del Estado de Bienestar y las políticas asistencialistas que apuntaron a las familias pobres del territorio y que se encarnan en la acción del Servicio Nacional de Salud, los Médicos Generales de Zona y el rol de las postas rurales. El énfasis en las realidades médico-sociales atravesadas por las carencias y el abandono político administrativo permite plantearnos otras preguntas y proyecciones, sobre todo en tiempos donde la discusión por la salud pública y los derechos sexuales y reproductivos son parte del debate constitucional en el marco de desigualdades provocadas por la privatización de los servicios, además de cómo se visibilizan las problemáticas de sujetas como las mujeres rurales.

\section{Referencias citadas}

Arcos, Carol. 2018. "Feminismos latinoamericanos: deseo, cuerpo y biopolítica de lo materno" en Debate Feminista, Año 28, Vol. 55, México, pp. 27-58.

Aresti, Nerea. 2006. "La categoría de género en la obra de Joan Scott", en Borderías, Cristina (ed.). Joan Scott y las políticas de la historia, Barcelona, Icaria Editorial, pp. 223-232.

Bolufer, Mónica. 2010. "Madres, maternidad: nuevas miradas desde la historiografía" en Franco Rubio, Gloria (ed.). Debates sobre la maternidad desde una perspectiva histórica (siglos XVI-XX), Barcelona, Icaria Editorial, pp. 51-81.

Givovic, Luis. 1973. "Salud Materno-Infantil" en Revista chilena de pediatría, vol. 44, n 6, Santiago, pp. 572-589. 
González, Gerardo y Ramírez, Valeria. 1979. "Las políticas relativas a la fecundidad" en Cuadernos del Celade, La Política de Población en América Latina/ 1974-1978, Santiago de Chile, CELADE, pp. 89115.

Illanes, María Angélica. 1993. En el nombre del pueblo, el Estado y la ciencia. Historia social de la salud pública, Chile, 1880-1973: hacia una historia social del Siglo XX, Santiago de Chile, Colectivo de Atención Primaria.

Ortiz, Yolanda, Fardella, Nora y Godoy, María. 1952. Actas de las primeras jornadas chilenas de salubridad organizada por la Sociedad Chilena de Salubridad y Medicina Pública, Santiago de Chile, Talleres de la Casa Nacional del Niño. Memoria Chilena, Biblioteca Nacional de Chile. Disponible en: http://www.memoriachilena.cl/602/w3-article-65965.html (Consultado el 27 de diciembre de 2020).

Oxman, Verónica. 1983. La participación de la mujer campesina en organizaciones: los Centros de Madres rurales, Santiago de Chile, Grupo de Investigaciones Agrarias, Academia de Humanismo Cristiano.

Pateman, Carole y Agra, María José. 1995. El contrato sexual. Vol. 87, Barcelona, Anthropos Editorial.

Poblete, Javiera. 2019. Ni madres ni padres. Sexualidad popular en Chile, 1927-1937, Santiago de Chile, CENALTES Ediciones.

Raczynski, Dagmar. 1980. "Reformas al sector salud: diálogos y debates" en Colección Estudios Cieplan, № 10, Chile, pp. 5-44.

Scott, Joan. 1996. "El género: Una categoría útil para el análisis histórico" en Lamas, Marta (comp.), El género: la construcción cultural de la diferencia sexual, México, PUEG, pp. 265-302.

Scott, Joan. 2011. Género: ¿todavía una categoría útil para el análisis? en La manzana de la discordia, Vol. 6, N¹, Cali, Colombia, pp. 95-101.

Tetelboin, Carolina y Salinas, Darío. 1984. "Estado y políticas de salud en Chile: el proceso de conformación de un nuevo proyecto para el sector salud, 1973-1979" en Estudios Sociológicos II, 2-3, México, pp. 351-385.

Tinsman, Heidi. 2008. "La tierra para el que la trabaja: política y género en la reforma agraria chilena” en Perspectivas, Revista de Trabajo Social, Universidad Católica Silva Henríquez, Año XIII, N 19, pp. 5367.

Vargas, Marcela. 2020. "No queremos ser servidas, queremos servir a Chile. Rol de los Centros de Madres (CEMA) en el sur rural de Chile, 1973-1983" en Revista Austral de Ciencias Sociales, (39), Valdivia, pp. 75-94.

Yuval-Davis, Nira. 1996. "Género y nación: articulaciones del origen, la cultura y la ciudadanía" en Arenal: Revista de historia de mujeres, ISSN 1134-6396, Vol. 3, N², España, pp. 163-175.

\section{Documentos}

Cuadernos médico-sociales, Colegio Médico (Santiago de Chile, 1959-1983).

Revista Amiga, Secretaría Nacional de la Mujer (Santiago de Chile, enero - noviembre de 1976).

"La Junta de Gobierno se dirige a las mujeres de Chile". 24 de abril de 1974. Discurso pronunciado por el General Augusto Pinochet como presidente de la Junta Militar de Gobierno. 
Servicio Nacional de Salud, Dirección General, Departamento Técnico. 1973-1983. Anuario Atenciones y recursos. Subdepartamento de Estadística, Ministerio de Salud, Gobierno de Chile.

ODEPLAN (Chile). 1978. Política de población: política poblacional aprobada por su excelencia el presidente de la República y publicada en el Plan Nacional Indicativo de Desarrollo: (1978-1983). Disponible en Memoria Chilena, Biblioteca Nacional de Chile http://www.memoriachilena.cl/602/w3article-127284.html (Consultado el 25 de septiembre de 2020). 